\title{
Simulation of automatic fan with LM35 temperature sensor using ATMEGA8535 microcontroller in Proteus application
}

\author{
Aljo Leonardo ${ }^{1 *}$, Weri Sugianto ${ }^{1}$ \\ ${ }^{1}$ Computer Engineering Program, AMIKOM University, 55281 Yogyakarta, Indonesia \\ *E-mail: aljo.leonardo@students.amikom.ac.id \\ * corresponding author
}

\begin{abstract}
The human body has a temperature and always releases energy at any time, especially body heat. Humans always react when heat occurs either due to temperature or other external and internal factors. When heat is generated from the temperature of the air, humans usually prefer a solution to use a fan and an air conditioner to eliminate the feeling of heat. However, the fan normally used is not practical since it should be turned on and turn off manually. To answer this problem, this study simulates an automatic fan by utilizing a microcontroller-based temperature sensor equipped with a temperature sensor LM35, ATmega8535, and other circuits. The fan works automatically and shows an easier operational process. It also requires more efficient energy because it works only when the temperature sensor detects the predetermined temperature. The role of sensors, series, is essential in this project. From the results of tests conducted on the simulation, the system can work effectively according to the product design.
\end{abstract}

ARTICLE INFO

\author{
Article history \\ Received: \\ 12 January 2020 \\ Revised: \\ 15 October 2020 \\ Accepted: \\ 15 October 2020 \\ Keywords \\ Automatic Fan \\ Temperature \\ LM35 Sensors \\ ATMega8535 \\ Proteus \\ CodeVisionAVR
}

This is an open access article under the $\underline{\mathrm{CC}-\mathrm{BY}-\mathrm{SA}}$ license.

\section{(ㄷ) (1) (2)}

\section{Introduction}

The condition of the earth recently is very concerning, especially the problem of global warming effects that often occur in various regions in the world, especially in Indonesia. The climate is uncertain, even in 2019, the longest drought occurred in the country. As a result, the heat generated is extraordinary, even temperatures can reach $35^{\circ} \mathrm{C}$ at midday or during the day. It was reported that the weather extremely hot.

For this reason, many people use various ways to deal with excess heat, especially during the dry season. There are various ways, from using air conditioners (AC) and electronic fans, but for AC, the cost of procuring $\mathrm{AC}$ is quite expensive, especially for the cost of the electricity itself, so many people 
Journal of Engineering and Applied Technology

Vol. 1, No. 2, March 2020, pp. 43-50

prefer electronic fans as a more appropriate solution because they are more affordable. However, the fan normally used is not practical since it should be manually operated to turn it on and turn it off, or adjust the speed.

In our community, electrical fans are mostly usually conducted by manual switches, particularly in rooms that turn on or off. They are becoming so distracted that after leaving the room they forgot to turn off switches. The global temperature is increasing quickly, so there is adapting to this varying temperature needs modern technologies. The need for automated device is the issue of today's concern

In general, erratic temperature changes allow users manually adjust the inventions and advancements and technologies of automatic electric fans. Heat can be reduced by different strategies, one of which is the fan temperature that a microcontroller applies. To reply to the need for better progress than before, fan making is programmed on the basis of the microcontroller.

A microcontroller-based system for automatic fans using a temperature sensor was used in this research. Particularly when the temperature of the room turns high and then begins to fall over time. Effective automatic fan to respond to the problems associated with the current manual fan control system, which varies according to room temperature.

Therefore, in this study, a simulation project is conducted. This system is so easy to understand and very useful, namely an automatic fan using a microcontroller-based temperature sensor system. The concept of this simulation is when the temperature is increasing and reach the predetermined temperature, the fan will automatically turn on temporarily, if the temperature decreases, the fan will automatically stop [1]. This fan also can automatically adjust the fan speed depending on the room temperature [2].

When the sensor detects the highest temperature, the fan will spin faster. Vice versa, the fan will stop if it reaches a lower temperature. To support this fan system to function optimally, a microcontroller-based device simulation circuit using LM35 and ATMEGA8535 temperature sensors is required [3], [4].

Based on the AVR enhanced RISC architecture, the ATmega8535 is a low-power CMOS 8-bit microcontroller. The ATmega8535 achieves outputs approaching 1 MIPS per MHz by executing instructions in a single clock cycle, enabling the system designer to optimize power consumption versus processing speed. This is simulated in the Proteus application version 8.7 with the CodeVisionAVR application.

\section{Method}

This study explores literature by collecting interrelated references between system design and the applied theory which were obtained and selected based on the relevance with the existing studies. The focus of this study is to design the circuit, to prepare the tools used to simulate the circuit, and to experiment and test the programming language about how to use the microcontroller circuit system 
Journal of Engineering and Applied Technology

Vol. 1, No. 2, March 2020, pp. 43-50

and the use of the $\mathrm{C}$ programming language for later system testing. The detailed method is categorized into several steps, namely:

(1) Designing

Using the simulation and testing techniques used in Proteus and studying the design material using the $\mathrm{C}$ programming language in the CV-AVR or code vision.

(2) Data Collection

The technique used in data collection is research through documentation obtained from various journal articles, reports, and other reliable sources, including books, and video tutorials. These data are in the form of theories, concepts, and videos from official literature.

(3) Data Analysis

The data analysis used the paraphrase technique, by re-emphasizing the ideas with easier words to understand.

(4) System Design Techniques

The design technique was the Proteus application for the simulation design using the CodeVisionAVR application using the $\mathrm{C}$ language

The materials used include:

(1) Proteus application 8.7,

(2) CodeVisionAVR application

(3) 1 laptop.

The circuit components used in Proteus

(1) ATMEGA8535

(2) CERAMIC2N7

(3) CRYSTAL

(4) L293D

(5) LED-BIGGY

(6) LM35

(7) MOTOR-DC

\section{Results and Discussion}

This system used the ATMega8535 connected to each of the components in the circuit. The microcontroller system will induce the fan to run automatically through a predetermined temperature setting. The LM35 will display the temperature information. The LED light will turn on when the first fan turns on. The LED light will remain lit which indicates that the fan is active according to the temperature sensor state.

The fan used in the simulation this time is two DC-motor fans. The working principle is that the first fan will turn on if it touches a temperature of $30^{\circ} \mathrm{C}$ and will turn off if it is below that temperature. While the second fan will turn on if it touches a temperature of $35^{\circ} \mathrm{C}$ or more and will automatically turn off if it touches a temperature below $35^{\circ} \mathrm{C}$. 
Journal of Engineering and Applied Technology

Vol. 1, No. 2, March 2020, pp. 43-50

The fan will lower the dynamo fan automatically when it reaches the lower temperature or below $30{ }^{\circ} \mathrm{C}$. The goal is to reduce the required power. That way it will be more optimal according to the level of temperature readability. The overview of automatic fan work procedure diagram is presented in Fig.1.

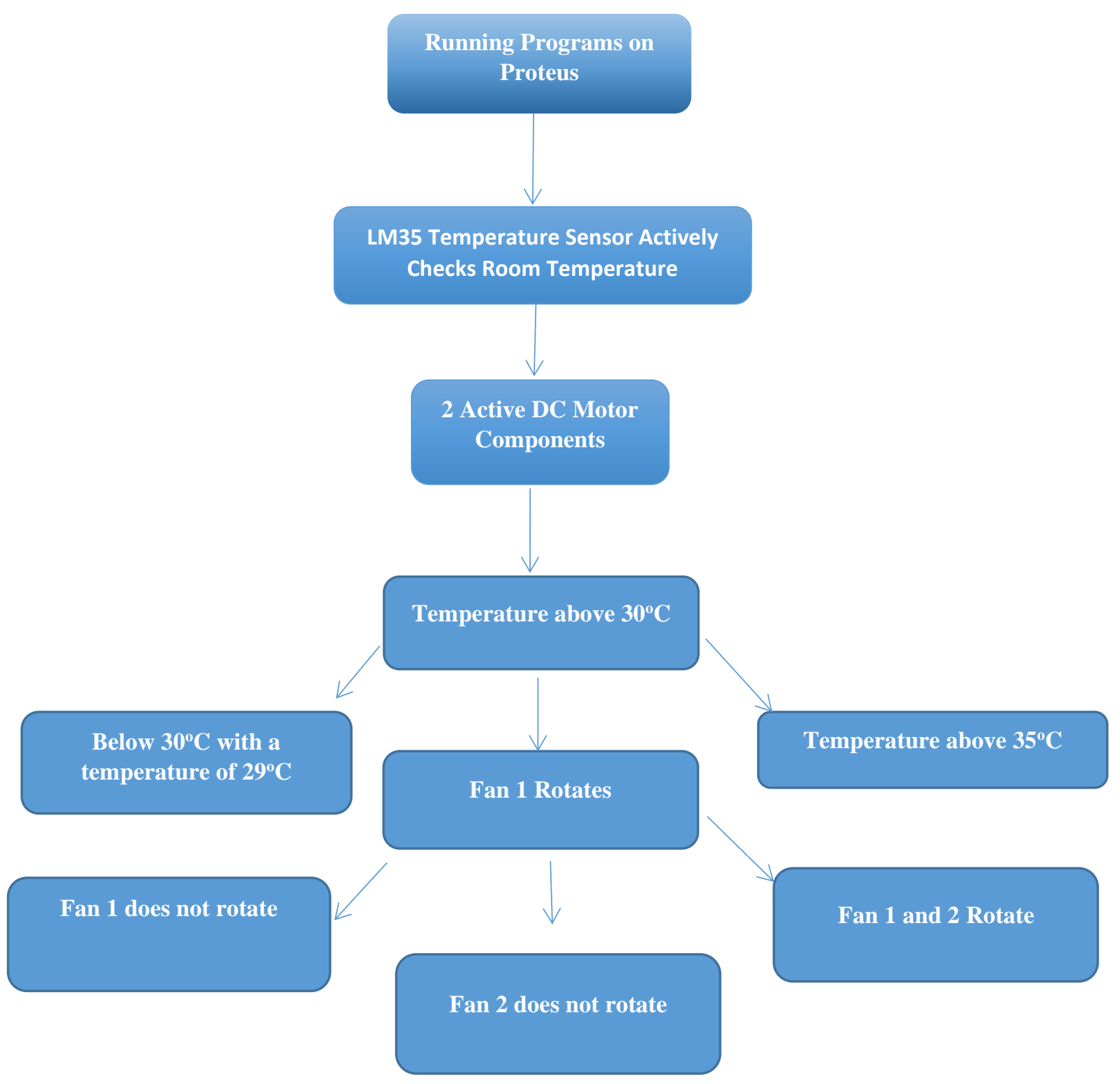

Fig. 1. Automatic Fan work procedure 
Journal of Engineering and Applied Technology

Vol. 1, No. 2, March 2020, pp. 43-50

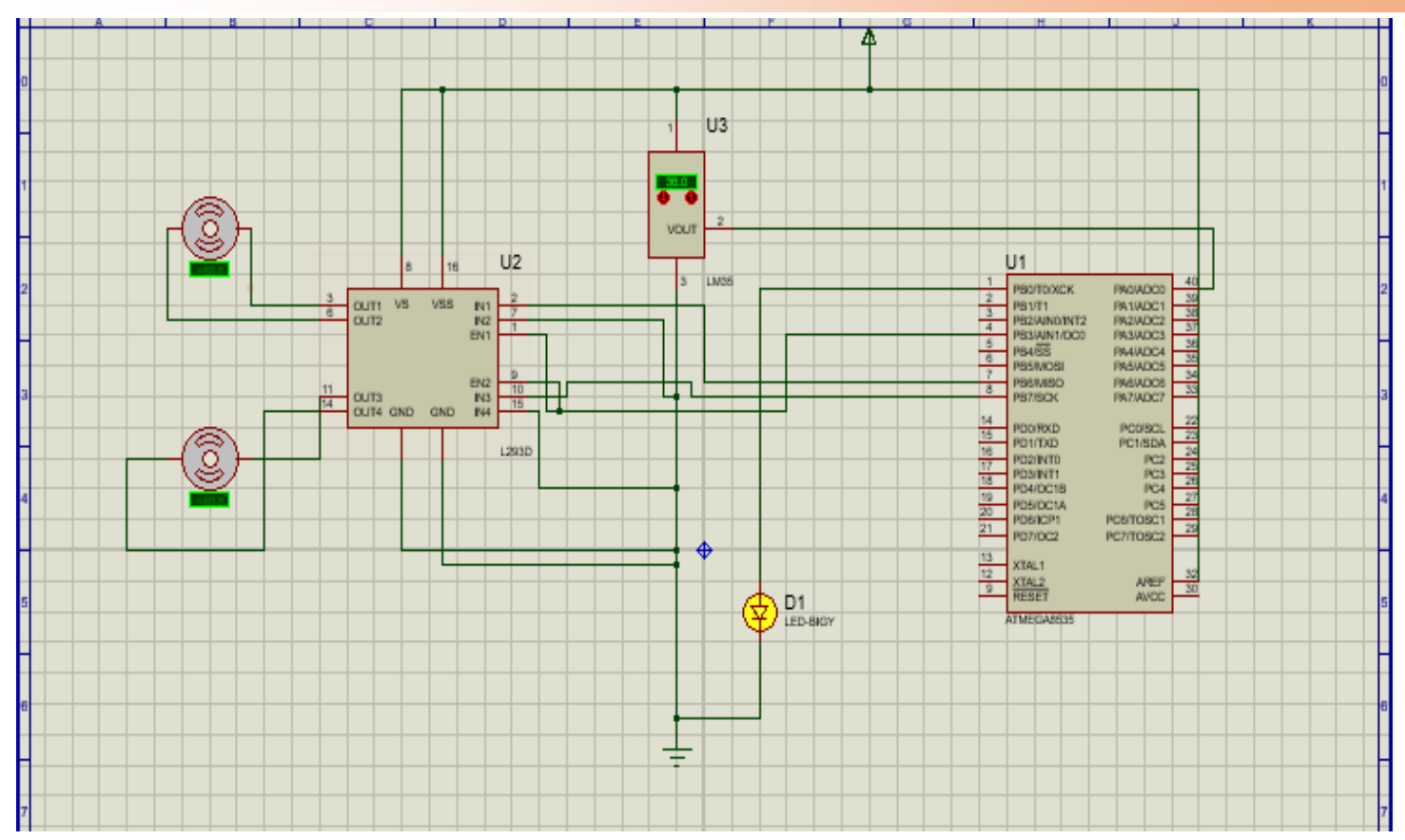

Fig. 2. The schematic circuit for automatic fan simulation using a temperature sensor

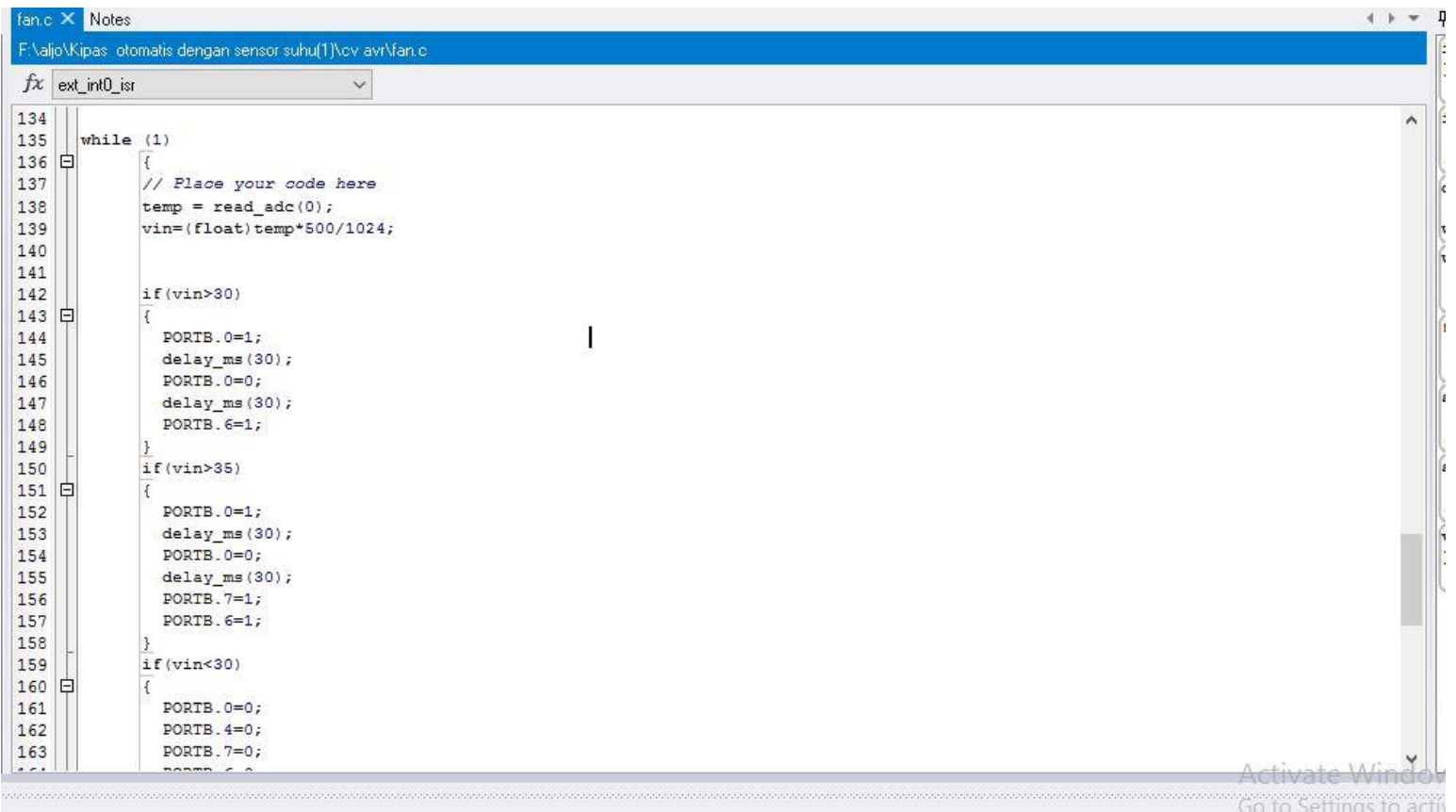

Fig. 3. The code used to run the program 
Journal of Engineering and Applied Technology

Vol. 1, No. 2, March 2020, pp. 43-50

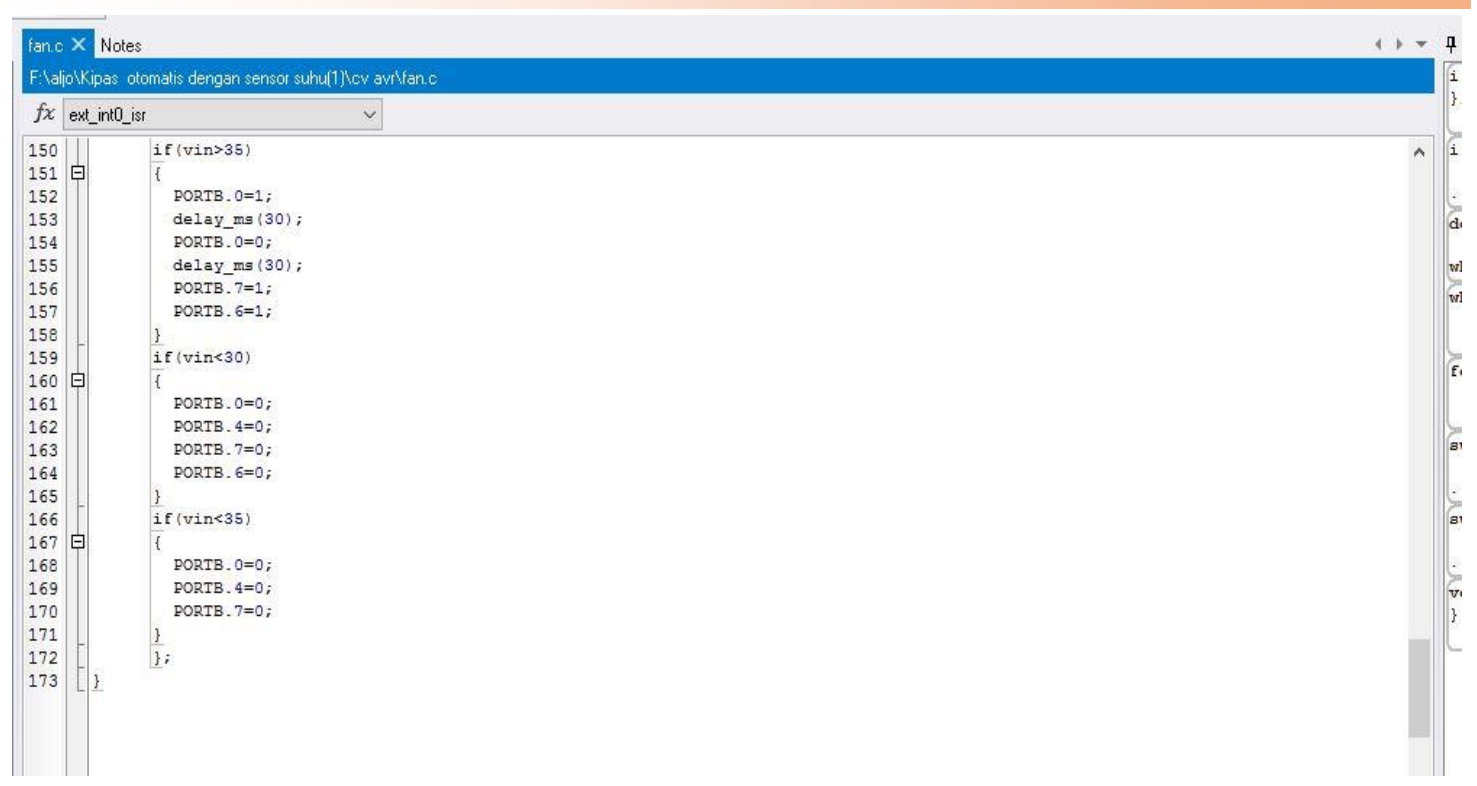

Fig. 4. The code used to run the program

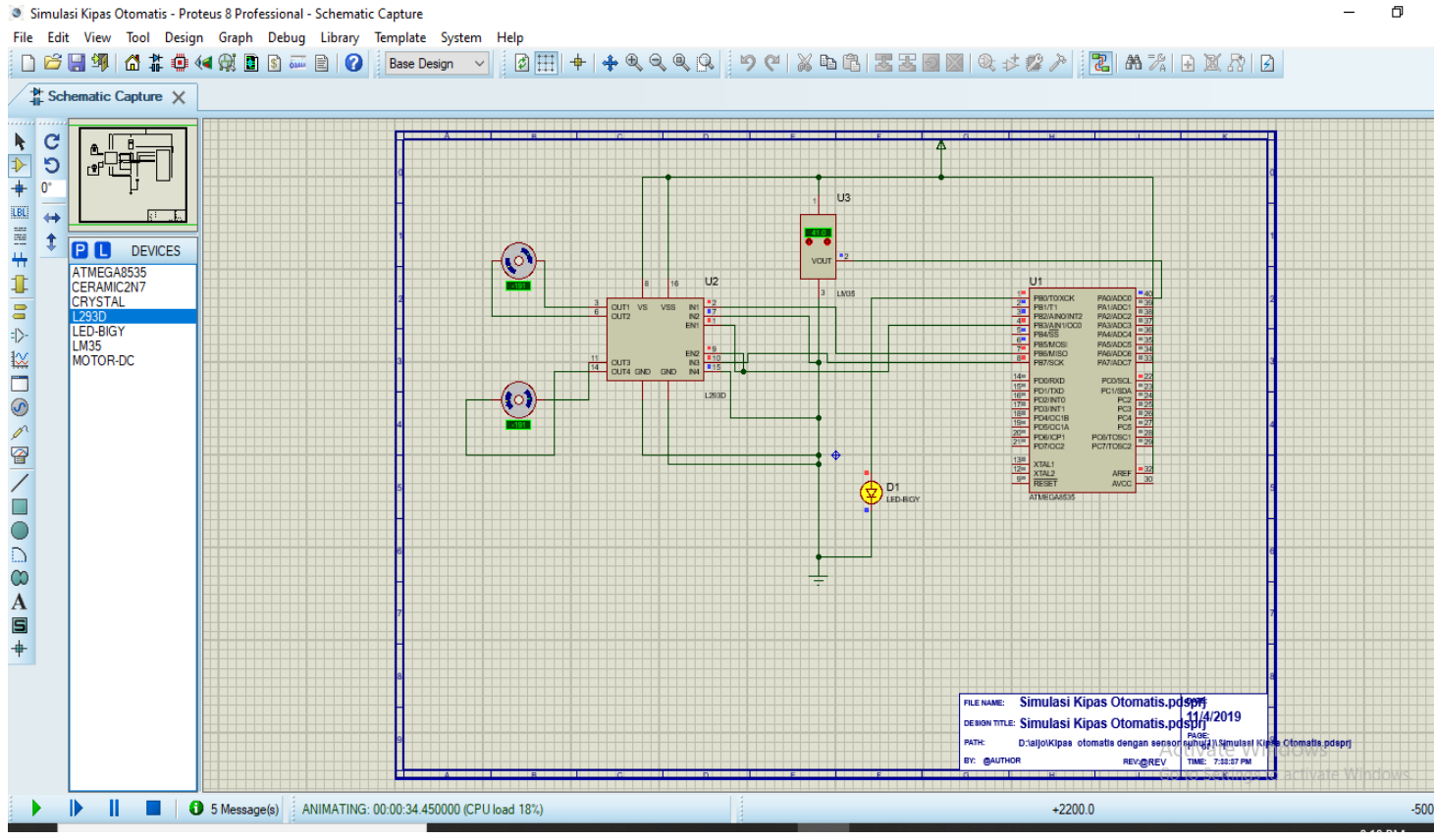

Fig. 5. The series that has been running and executed

The above is a series that has been run or executed. It can be seen that the LED light is on with the temperature set so that the fan moves. The experiment results are presented in Table1. Table 1 shows the results of the tests and experiments carried out. The explanation of the result is discussed as follows: 
Journal of Engineering and Applied Technology

Vol. 1, No. 2, March 2020, pp. 43-50

(1) When the temperature is still at $15^{\circ} \mathrm{C}$ to $25^{\circ} \mathrm{C}$ Both fans do not rotate with the condition of the LED lights are still Off.

(2) When the temperature is at $30^{\circ} \mathrm{C}$, the first fan will turn on automatically with the LED light that is on but the second fan does not rotate

(3) When the temperature is at $35^{\circ} \mathrm{C}$. The second fan will turn on automatically followed by the first fan with the LED light that is on.

(4) When the temperature is lower than $35^{\circ} \mathrm{C}$, the second fan slowly rotates. It is getting slower and it will turn off if the first fan still has no change in temperature followed by the LED light going that is off.

(5) When the temperature decreases from $30^{\circ} \mathrm{C}$, then the first fan will slowly rotate and will turn off when the time is up, it is the same as in the second fan, with the LED light that is off.

Table 1. Experiment results

\begin{tabular}{cclc}
\hline No & Temperature & \multicolumn{1}{c}{ Motor speed } & $\begin{array}{c}\text { LED } \\
\text { condition }\end{array}$ \\
\hline 1 & 15 & The two fans do not rotate & Off \\
2 & 20 & The two fans do not rotate & Off \\
3 & 25 & The two fans do not rotate & Off \\
4 & 30 & The first fan rotates quickly & On \\
5 & 30 & The second fan does not rotate & On \\
6 & 35 & The first fan rotates quickly & On \\
7 & 40 & The two fans rotate very quickly & On \\
8 & $>45$ & The two fans rotate very quickly & On \\
9 & $<29$ & The two fans rotate slowly & Off \\
& & The two fans slowly rotate. It is getting slower & Off \\
10 & $<25$ & and finally turns off after a specified of time & \\
& & & \\
\hline
\end{tabular}

\section{Conclusion}

Based on the research that has been conducted through the design stages and the simulation of the automatic fan circuit, it is concluded several points related to the implementation and results. Automatic fan control system temperature sensor uses an ATMega8535 microcontroller which functions as the main controller or the main core of a circuit as a system driver. This automatic fan also uses a sensor namely the LM35 sensor as a tool for detecting the temperature in this Automatic Fan project.

The fan operates at a temperature of $30^{\circ} \mathrm{C}$ for the first fan and $35^{\circ} \mathrm{C}$ for the second fan. Thus, when the temperature is below $30^{\circ} \mathrm{C}$, the fan will stop moving or rotating. At temperatures of $30^{\circ} \mathrm{C}$ and $35^{\circ} \mathrm{C}$, it means that the temperature is high therefore the fan will turn on automatically to lower the temperature. However, it will turn off when the room temperature decreases dramatically. The programming language used is CodeVisionAVR which is used to program the Integrated Circuit (IC) on the ATMega8535 microcontroller. 


\section{References}

[1] Pineng, M., Toraja, T., \& Toraja, T. Sistem cerdas pengatur suhu secara otomatis sebagai alternatif. 2018, 18-22. 2018.

[2] Langi, S. I. "Kipas Angin Otomatis Dengan Menggunakan Sensor Suhu". E-Journal Teknik Elektro dan Komputer, 3(5), 41-48. 2014.

[3] Mareta, R., Mutmainah, S.,Yoga, N., Ashari, R. \& Firmansyah, R. A. Kipas angin otomatis menggunakan sensor suhu dan sensor kipas angin otomatis menggunakan sensor suhu dan sensor infrared dengan mikrokontroler ATMEGA32. Thesis. AMIKOM Yogyakarta. 2019

[4] Suryadi, L., Darmanto, T., \& Putra, A. Y. A. "Perancangan Sistem Kontrol Kipas Angin Otomatis Menggunakan Sensor Suhu LM35 Berbasis Mikrokontroler ATMega16". Jurnal InTekSis.Vol.2. No.2. pp. 76-82. 